\title{
PERANCANGAN DESAIN PRODUK ALAT TULIS KANTOR DENGAN MENGGUNAKAN METODE QUALITY FUNCTION DEPLOYMENT
}

\author{
Muhammad $^{1}$, Meutia Fadilla ${ }^{2}$ \\ ${ }^{1}$ Dosen Departemen Teknik Industri, Fakultas Teknik, Universitas Malikussaleh \\ Jl. Cot Tengku Nie Reuleut, Kabupaten Utara, Reuleut Tim., Muara Batu, Kabupaten Aceh \\ Utara, Aceh \\ Email : irmuhammad@unimal.ac.id \\ ${ }^{2}$ Mahasiswa Departemen Teknik Industri, Fakultas Teknik, Universitas Sumatera Utara \\ Jl. Almamater Kampus USU, Medan 20155 \\ Email : meutiafadilla@yahoo.com
}

\begin{abstract}
Abstrak. Untuk mengembangkan suatu produk, dalam hal ini tempat alat tulis kantor, diperlukan suatu metode agar pengembangan dapat diketahui dengan baik, pada penelitian ini, penulis menggunakan metode Quality Function Deployment (QFD), dimana pengertiannya adalah suatu metode yang mencakup untuk mengetahui kebutuhan apa yang diperlukan konsumen pada suatu produk, dan kebutuhan tersebut haruslah diintegrasikan pada spesifikasi-spesifikasi produk yang dikembangkan. Hasil pendekatan dengan metode QFD menunjukan bahwa kinerja karakteristik teknik dengan nilai tertinggi adalah karakteristik teknik kepadatan cetakan pasir, kadar aluminium, kecepatan putaran mesin gerinda, ketelitian penggerindaan dan jarak semprot pilox dengan masing-masing nilai derajat kepentingan sebesar $15 \%$, sedangkan dari sepuluh atribut kebutuhan konsumen yang memperoleh nilai relative weight tertinggi adalah variabel jumlah ruang pada alat tulis kantor dengan nilai relative weight 33,63\%.
\end{abstract}

Kata Kunci: Tempat Alat Tulis Kantor, Quality Function Deployment (QFD), House of Quality, Perancangan Produk

\begin{abstract}
To develop a product, in this case the place of stationery, required a method for the development can be known well, in this study, the authors use the method of Quality Function Deployment (QFD), where the definition is a method that includes to find out what needs are needed by consumers on a product, and those needs must be integrated into the product specifications developed. The result of approach with QFD method shows that the performance of technique characteristic with the highest value is characteristic of sand mold density technique, aluminum content, rotational speed of grinding machine, grinding accuracy and spray spray with each $15 \%$ importance rating, while from ten attribute requirement consumers who get the highest relative weight is the variable amount of space on office stationery with a relative weight of $33.63 \%$.
\end{abstract}

Keywords: Office Stationery Place, Quality Function Deployment (QFD), House of Quality, Product Design 


\section{Pendahuluan}

Persaingan bisnis menuntut perusahaan agar mampu menerapkan rencana strategis untuk memenuhi kebutuhan konsumen dalam pengembangan produk dengan peningkatan kualitas, performansi, dan pengurangan biaya serta waktu produksi. Lingkungan yang kompetitif saat ini membuat kegiatan ini lebih sulit dilakukan dari sebelumnya. Pelanggan tidak hanya menuntut tingkat kualitas yang lebih tinggi dalam produk baru, tetapi juga menuntut i novasi terbaru. Produk berkual i tasti nggi merupakan prasyarat utama untuk perusahaan kompetitif (Paulo, 2007). Perusahaan harus mampu melakukan inovasi untuk memenuhi kebutuhan pelanggan (LeeMortimer, 1995). Perusahaan dapat melakukan inovasi dengan menerapkan tools dan metode berkaitan dengan upaya inovasi (Davidsen, 2004). Metode dan tools diterapkan perusahaan untuk mengkomersialkan produk dan menciptakan inovasi yang akan meningkatkan nilai produk. Quality Function Deployment (QFD) merupakan salah satu metode untuk pengembangan produk berorientasi pelanggan (Paulo, 2007). QFD merupakan perencanaan proses yang membantu rencana organisasi dal am penerapan berbagai alat pendukung teknis secara efektif dan pelengkap antara satu sama lain untuk mempriori taskan setiap permasal ahan. QFD adalah suatu cara untuk meningkatkan kualitas barang atau jasa dengan memahami kebutuhan konsumen kemudian menghubungkannya dengan karakteristik teknis untuk menghasilkan suatu barang atau jasa pada setiap tahap pembuatan barang atau jasa yang dihasilkan (Rosnani Ginti ng, 2010). QFD di gunakan untuk membantu bisnis memusatkan perhatian pada kebutuhan para pelanggan ketika menyusun spesifikasi desain dan fabrikasi. QFD terbagi menjadi empat fase yang di gunakan untuk menghubungkan kebutuhan konsumen dengan karakteristik perancangan produk, dan kemudian menerjemahkannya ke dalam karakteristik part, operasi manufaktur, dan karakteristik produksi. QFD tahap identifikasi kebutuhan konsumen, dan karakteristik part di aplikasikan pada tahap perancangan produk (Chen, 2006). Tujuan utama dari QFD adalah menentukan prioritas kriteria rancangan yang menjadi fokus utama dalam perancangan dan pengembangan produk (Reilly, 1999). Alat perencanaan utama yang di gunakan dalam QFD adalah House of Quality. House of Quality menerjemahkan suara pelanggan ke dalam persyaratan desain yang memenuhi target nilai tertentu dan menyesuaikannya dengan organisasi atau perusahaan yang akan merancang persyaratan desain tersebut (Mahesh,2010).

\section{Bahan dan Metode Penelitian}

Penelitian ini menggunakan instrumen kuesioner. Kuesioner yang digunakan didasarkan pada bentuknya ialah kuesioner terbuka dan tertutup. Kuesioner terbuka di gunakan sebagai survei awal untuk membantu penentuan atribut keinginan responden terhadap produk tempat alat tulis kantor sedangkan kuesioner tertutup yang digunakan adalah kuesioner dengan menggunakan ska la likert. Jumlah sampel pada penelitian ini adalah 97 orang.

\section{Analisis Data dan Pembahasan}

\subsection{Hasil Kuesioner}

1. Mengidentifikasikan keinginan konsumen ke dalam bentuk atribut produk.

Pada tahap ini, akan diuji sejauh mana tingkat kepuasan konsumen terhadap produk. Adapun metode yang digunakan dalam pengumpulan data untukmengetahui keinginan konsumen adalah dengan menyebarkan kuesioner. Penyebaran kuesioner ini dilakukan 
melalui dua tahap, yaitu sebagai berikut:

a. Kuesioner Terbuka

Kuesioner ini berisikan keinginan konsumen terhadap atribut-atribut produk yang telah ditentukan dan dapat dijawab secara bebas mengenai atribut yang ditanyakan. Dalam hal ini, kuesioner disebarkan kepada 97orang responden yang merupakan mahasiswa STMIK Neumann Medan.

b. Kuesioner Tertutup Kuesioner ini berisikan pernyataan, dimana pernyataan tersebut diambil berdasarkan modus dari kuesioner terbuka. Responden diminta untuk mengisi kolom-kolom yang disediakan mengenai kinerja dari masing- masing tempat alat tulis kantor yang dapat dilihat pada tabel 1.

\section{Tabel 1. Atribut Tempat alat tulis kantor}

\begin{tabular}{|c|c|c|}
\hline Primer & Sekunder & Tersier \\
\hline \multirow{13}{*}{ Desain } & Ukuran & $\begin{array}{c}(18 \times 15 \times 15) \\
\mathrm{cm}^{3}\end{array}$ \\
\hline & Warna & Putih \\
\hline & Motif & Garis-garis \\
\hline & Hiasan & Bunga \\
\hline & $\begin{array}{l}\text { Warna } \\
\text { Hiasan }\end{array}$ & Putih \\
\hline & Jumlah & \\
\hline & Ruang & 4 \\
\hline & Bentuk & \\
\hline & Fungsi & Persegi \\
\hline & Tambahan & \\
\hline & Warna & \\
\hline & Fungsi & Ungu \\
\hline & Tambahan & \\
\hline Bahan & $\begin{array}{c}\text { Bahan } \\
\text { fungsi } \\
\text { tambahan }\end{array}$ & Plastik \\
\hline Fungsi & $\begin{array}{c}\text { Fungsi } \\
\text { Tambahan }\end{array}$ & Bingkai \\
\hline
\end{tabular}

\subsection{Validitas dan Reliabilitas Data \\ Pengolahan data kuisioner tertutup} menghasilkan nilai $r_{\text {hitung }}$ pada uji validitas masing-masing atribut produk lebih besar dari nilai kritik $(\mathrm{r}=0,200)$ yang berarti diperoleh hasil yang valid untuk semua jenis atribut. Kuesioner merupakan instrumen yang valid dan dapat dipergunakan untuk mendapatkan informasi dari responden.

Pengolahan data kuesioner tertutup manghasilkan nilai reliabilitas masingmasing atribut produk lebih besar dari 0,6 yang berarti hasil yang diperoleh reliable untuk semua jenis atribut. Oleh karena itu, kuesioner bersifat reliable dan dapat digunakan kembali apabila dibutuhkan.

\subsection{Menentukan tingkat kepentingan relatif dari atribut produk. \\ Penentuan tingkat kepentingan} relatif atribut ini dilakukan dengan memberikan bobot persentase pada masing-masing atribut dengan menggunakan skala prioritas. Dalam hal ini, digunakan modus yang didapat dari kuesioner tertutup sesuai dengan skala Likert yang dapat dilihat pada Tabel 2 .

Tabel 2. Modus Atribut Tempat alat tulis kantor

\begin{tabular}{|c|c|c|c|}
\hline Primer & Sekunder & Tersier & $\begin{array}{l}\text { Tingkat } \\
\text { Kepentingan }\end{array}$ \\
\hline \multirow{8}{*}{ Desain } & Ukuran & 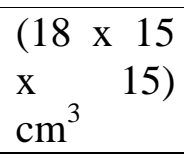 & 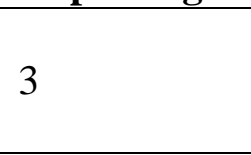 \\
\hline & Warna & Putih & 2 \\
\hline & Motif & $\begin{array}{l}\text { Garis- } \\
\text { garis }\end{array}$ & 3 \\
\hline & Hiasan & Bunga & 2 \\
\hline & $\begin{array}{l}\text { Warna } \\
\text { Hiasan }\end{array}$ & Putih & 3 \\
\hline & $\begin{array}{l}\text { Jumlah } \\
\text { Ruang }\end{array}$ & 4 & 3 \\
\hline & $\begin{array}{l}\text { Bentuk } \\
\text { Fungsi } \\
\text { Tambahan }\end{array}$ & Persegi & 2 \\
\hline & $\begin{array}{l}\text { Warna } \\
\text { Fungsi } \\
\text { Tambahan }\end{array}$ & Ungu & 3 \\
\hline Bahan & $\begin{array}{l}\text { Bahan } \\
\text { fungsi } \\
\text { tambahan }\end{array}$ & Plastik & 2 \\
\hline Fungsi & $\begin{array}{l}\text { Fungsi } \\
\text { Tambahan }\end{array}$ & Bingkai & 3 \\
\hline
\end{tabular}




\subsection{Mengevaluasi atribut produk} pesaing.

Atribut-atribut produk untuk pesaing 1 , pesaing 2 , dan pesaing 3 yang telah ditabulasi dapat dilihat pada Tabel 3.

Tabel 3. Atribut Produk Tempat alat tulis kantor Pesaing I, II, dan III

\begin{tabular}{|c|c|c|c|c|c|}
\hline \multirow{2}{*}{ Primer } & \multirow{2}{*}{ Sekunder } & \multirow{2}{*}{ Tersier } & \multicolumn{3}{|c|}{$\begin{array}{l}\text { Tingkat } \\
\text { Kepentingan }\end{array}$} \\
\hline & & & P1 & P2 & P3 \\
\hline \multirow{8}{*}{ Desain } & Ukuran & $\begin{array}{lr}(18 & x \\
15 & x \\
15) & \mathrm{cm}^{3} \\
\end{array}$ & 2 & 2 & 3 \\
\hline & Warna & Putih & 2 & 2 & 2 \\
\hline & Motif & $\begin{array}{l}\text { Garis- } \\
\text { garis }\end{array}$ & 2 & 2 & 2 \\
\hline & Hiasan & Bunga & 3 & 3 & 2 \\
\hline & $\begin{array}{l}\text { Warna } \\
\text { Hiasan }\end{array}$ & Putih & 2 & 3 & 2 \\
\hline & $\begin{array}{l}\text { Jumlah } \\
\text { Ruang }\end{array}$ & 4 & 3 & 2 & 2 \\
\hline & $\begin{array}{l}\text { Bentuk } \\
\text { Fungsi } \\
\text { Tambahan }\end{array}$ & Persegi & 2 & 2 & 2 \\
\hline & $\begin{array}{l}\text { Warna } \\
\text { Fungsi } \\
\text { Tambahan }\end{array}$ & Ungu & 3 & 2 & 2 \\
\hline Bahan & $\begin{array}{l}\text { Bahan } \\
\text { fungsi } \\
\text { tambahan }\end{array}$ & Plastik & 3 & 2 & 2 \\
\hline Fungsi & $\begin{array}{l}\text { Fungsi } \\
\text { Tambahan }\end{array}$ & Bingkai & 2 & 2 & 3 \\
\hline
\end{tabular}

\subsection{House of Quality}

Selanjutnya dapat digambarkan house of quality yang merupakan gabungan semua karakteristik teknik, atribut yang diinginkan konsumen, posisi tempat alat tulis kantor terhadap atribut yang sama. Semuanya dibuat dalam rumah mutu dengan menggunakan metode QFD, seperti pada Gambar 1. 
$\mathrm{V}=$ Hubungan positif kuat, bobot $=4$

$\mathrm{v}=$ Hubungan positif sedang, bobot $=3$

$\mathrm{x}=$ Hubungan negatif sedang, bobot $=2$

$\mathrm{X}=$ Hubungan negatif kuat, bobot $=1$

\begin{tabular}{|c|c|c|c|c|c|c|c|c|c|c|c|c|}
\hline & స్ & 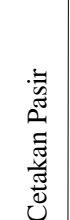 & .尹ٍ & 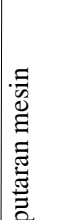 & 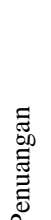 & 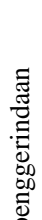 & $\begin{array}{l}\stackrel{x}{0} \\
\stackrel{a}{0} \\
\stackrel{0}{0}\end{array}$ & \multicolumn{5}{|c|}{$\begin{aligned} & \text { Persepsi Konsumen } \\
5 & =\text { Sangat baik } \\
4 & =\text { Baik } \\
3 & =\text { Cukup } \\
2 & =\text { Tidak baik } \\
1 & =\text { Sangat tidak baik }\end{aligned}$} \\
\hline & $\bar{\Xi}$ & 㽕 & $\begin{array}{l}\bar{\pi} \\
\text { ]ี }\end{array}$ & 䒕 & 䒕 & $:$ & $\stackrel{0}{\mathscr{N}}$ & \multicolumn{5}{|c|}{ Persepsi Konsumen } \\
\hline & త & 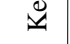 & $\tilde{\check{\Sigma}}$ & 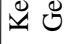 & $\mathscr{1}$ & 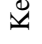 & పี & 5 & 4 & 3 & 2 & 1 \\
\hline 2 & $\mathrm{~V}$ & V & V & V & $X$ & V & $X$ & & $\begin{array}{c}\mathrm{A}, \mathrm{B}, \\
\mathrm{C}\end{array}$ & & III & \\
\hline 1 & $\mathrm{~V}$ & $\mathrm{v}$ & $\mathrm{x}$ & $\mathrm{V}$ & V & $\mathrm{V}$ & $\mathrm{x}$ & $\mathrm{C}$ & $\mathrm{B}$ & & & A, III \\
\hline 3 & $X$ & $\mathrm{x}$ & $\mathrm{x}$ & $\mathrm{x}$ & $\mathrm{V}$ & V & $X$ & $\mathrm{C}$ & B & III,A & & \\
\hline 5 & $X$ & $\mathrm{x}$ & $\mathrm{v}$ & $\mathrm{X}$ & $\mathrm{X}$ & $\mathrm{x}$ & V & III & & A,B & & $\mathrm{C}$ \\
\hline 4 & $\mathrm{X}$ & $\mathrm{X}$ & $\mathrm{x}$ & $\mathrm{x}$ & $\mathrm{x}$ & $\mathrm{X}$ & V & $\mathrm{C}$ & III & & & $\mathrm{A}, \mathrm{B}$ \\
\hline 2 & $X$ & $\mathrm{v}$ & $\mathrm{X}$ & $\mathrm{x}$ & $\mathrm{V}$ & $\mathrm{x}$ & $\mathrm{V}$ & & $\mathrm{C}$ & & $\begin{array}{c}\text { III,A, } \\
\text { B }\end{array}$ & \\
\hline 4 & $\mathrm{X}$ & $\mathrm{X}$ & $\mathrm{v}$ & $X$ & $\mathrm{X}$ & $X$ & $\mathrm{~V}$ & B & III,A & $\mathrm{C}$ & & \\
\hline 3 & $X$ & V & $X$ & $\mathrm{v}$ & $\mathrm{X}$ & $X$ & $X$ & & & III,B & $\mathrm{A}, \mathrm{C}$ & \\
\hline 3 & $\mathrm{x}$ & V & $\mathrm{v}$ & $\mathrm{v}$ & V & V & $\mathrm{x}$ & A & & III,B & $\mathrm{C}$ & \\
\hline 2 & X & $X$ & $\mathrm{~V}$ & v & X & $\mathrm{x}$ & $\mathrm{X}$ & & & & $\begin{array}{c}\text { III,B } \\
\text { C }\end{array}$ & A \\
\hline & $\mathrm{m} / \mathrm{s}$ & $\mathrm{kg} / \mathrm{m}^{3}$ & $\%$ & $\mathrm{rpm}$ & $\mathrm{cm}$ & $\%$ & $\mathrm{~cm}$ & & II & Kelom & pok III & \\
\hline & 2 & 3 & 3 & 3 & 3 & 3 & 3 & & A & Pesain & & \\
\hline & 10 & 15 & 15 & 15 & 14 & 15 & 15 & & B & Pesain & & \\
\hline & 10 & 15 & 15 & 15 & 15 & 15 & 15 & & $\mathrm{C}$ & Pesain & g 3 & \\
\hline
\end{tabular}

Bentuk tempat gelas kotak

Ukuran tempat gelas $20 \times 16 \times 5 \mathrm{~cm}$

Banyak lubang tempat gelas 12 buah

Warna tempat gelas putih

Motif tempat gelas garis-garis

Hiasan tempat gelas adalah stiker

Warna fungsi tambahan coklat

Letak fungsi tambahan di samping

Fungsi tambahan adalah laci

Bahan fungsi tambahan adalah kayu

\begin{tabular}{|l|c|c|c|c|c|c|c|c|}
\hline Satuan & $\mathrm{m} / \mathrm{s}$ & $\mathrm{kg} / \mathrm{m}^{3}$ & $\%$ & $\mathrm{rpm}$ & $\mathrm{cm}$ & $\%$ & $\mathrm{~cm}$ \\
\hline Tingkat Kesulitan & 2 & 3 & 3 & 3 & 3 & 3 & 3 \\
\hline Derajat Kepentingan (\%) & 10 & 15 & 15 & 15 & 14 & 15 & 15 \\
\hline Perkiraan Biaya (\%) & 10 & 15 & 15 & 15 & 15 & 15 & 15 \\
\hline
\end{tabular}

\section{Perkiraan biaya}

$1-10=$ Murah

$11-20=$ Mahal

21-30 = Sangat Mahal
$1-10=$ Cukup penting

$11-20=$ Penting

$21-30=$ Sangat penting

Gambar 1. Quality Function Deployment (QFD) Tempat alat tulis kantor 
a. Tingkat Kesulitan : Hampir semua karakteristik teknik memiliki tingkat kesulitan yang sulit tetapi untuk karakteristik laju penuangan memiliki tingkat kesulitan yang cukup mudah.

b. Derajat Kepentingan : Semua karakteristik teknik memiliki derajat kepentingan yangpentingtetapi untuk karakteristik laju penuangan memiliki tingkat kepentingan yangcukup penting.

c. Perkiraan Biaya :Semua karakteristik teknik memiliki perkiraan biaya yang mahal tetapi untuk karakteritik laju penuangan memiliki biaya yang murah.

Dari Gambar 1 dapat dilihat total tingkat kepentingan a tribut perancangan produk ditunjukkan dengan bobot absolut sedangkan bobot relatif menunjukan nilai bobot perencanaan relatif dari suatu variabel. Importance weight menunjukkan total tingkat kepentingan responden terhadap suatu atribut perancangan produk, sedangkan relative weight menunjukan nilai bobot kepentingan relative terhadap atribut perancangan produk lainnya (Lou Couhen,1995). Atribut perancangan produk tempat alat tulis kantor yang memiliki relative weight tertinggi adalah pada kepadatan cetakan pasir, kadar aluminium, kecepatan putaran mesin gerinda, ketelitian penggerindaan dan jarak semprot pilox dengan masing-masing nilai derajat kepentingan sebesar $15 \%$.

\section{Kesimpulan}

Kesimpulan yang dapat diperoleh dari pengolahan QFD diperoleh kinerja karakteristik teknik dengan nilai tertinggi adalah karakteristik teknik kepadatan cetakan pasir, kadar aluminium, kecepatan putaran mesin gerinda, ketelitian penggerindaan dan jarak semprot pilox dengan masing-masing nilai derajat kepentingan sebesar $15 \%$, sedangkan dari sepuluh atribut kebutuhan konsumen yang memperoleh nilai relative weight tertinggi adalah variabel jumlah ruang pada alat tulis kantor dengan nilai relative weight $33,63 \%$.

\section{DAFTAR PUSTAKA}

Augusto, Paulo. 2007. Innova ti ve New Product Devel opment : A Study of Selected QFD case Studi es . Bra zi 1:Uni versity of Sao Paulo.

Davidsen, B.A. (2004), "Innovation and product devel opment: methods a nd tools", Tel ektronik, Vol. 2.

Ginting, Rosnani. 2010. Perancangan Produk. Yogyakarta: Graha Ilmu.

J, Mahes h Patil. 2010. Quality Function Deployment (QFD) for Product Design. Indi a : TIME 2010

Reilly, Norman B, The Team based product development guidebook, ASQ Quality Press, Mi 1 wa ukee Wisconsi n, 1999.

Si nul i ngga, Suka ria. 2011. Metode Penelitian. Medan: USU Press. 